Review Article

\title{
Recent advances in pharmacotherapy of acute coronary syndrome
}

\author{
Vidhi Thaker ${ }^{1}$, Kamlesh Patel $^{2}$
}

${ }^{1}$ Department of Pharmacology, G. C. S. Medical College, Hospital and Research Centre, Ahmedabad, India ${ }^{2}$ Department of Pharmacology, N. H. L. Municipal Medical College, Ahmedabad, India

Received: 06 August 2016 Accepted: 03 September 2016

*Correspondence to:

Dr. Vidhi Thaker,

Email: vidhi71284@yahoo.co.in

Copyright: $\odot$ the author(s), publisher and licensee Medip Academy. This is an openaccess article distributed under the terms of the Creative Commons Attribution NonCommercial License, which permits unrestricted noncommercial use, distribution, and reproduction in any medium, provided the original work is properly cited.

\begin{abstract}
Acute coronary syndrome (ACS) describes the range of myocardial ischemic states that includes unstable angina, non-ST elevated myocardial infarction (MI), or ST-elevated MI. ACS is associated with substantial morbidity and mortality and places a large financial burden on the health care system. The diagnosis of ACS begins with a thorough clinical assessment of a patient's presenting symptoms, electrocardiogram and cardiac troponin levels as well as a review of past medical history. Early risk stratification can assist clinicians in determining whether an early invasive management strategy or an initial conservative strategy should be pursued and can help determine appropriate pharmacologic therapies. Key components in the management of ACS include coronary revascularization when indicated; prompt initiation of dual antiplatelet therapy and anticoagulation; and consideration of adjuvant agents including beta blockers, inhibitors of the renin angiotensin system, and HmG-coenzyme A reductase inhibitors. It is essential for clinicians to take an individualized approach to treatment and consider long-term safety and efficacy when managing patients with a history of ACS after hospital discharge. This review identifies promising new or emerging techniques, as well as established tools, and reviews their current or potential role in clinical practice.
\end{abstract}

Keywords: ACS, Revascularization, Medical therapy

\section{INTRODUCTION}

Cardiovascular diseases (CVDs) are the main cause of mortality globally and are the leading cause of death in India also. Several surveys conducted across the country over the past few decades have shown a rising prevalence of major risk factors for CVD in Asian population. The problem of increasing risk factors for CVD in India is because of lack of surveillance system, proper diagnosis and appropriate treatment. ${ }^{1}$

The term acute coronary syndrome (ACS) refers to any group of clinical symptoms compatible with acute myocardial ischemia and covers the spectrum of clinical conditions ranging from unstable angina (UA) to non STsegment elevation myocardial infarction (NSTEMI) to ST-segment elevation myocardial infarction (STEMI).
STEMI occurs by developing a complete occlusion of a major coronary artery previously affected by atherosclerosis. Unstable angina and NSTEMI are closely related conditions: their pathophysiologic origins and clinical presentations are similar, but they differ in severity. It is almost associated with rupture of an atherosclerotic plaque and partial or complete thrombosis of the infarct-related artery. A diagnosis of NSTEMI can be made when the ischemia causes severe myocardial damage that result in the release of a biomarker of myocardial necrosis into the circulation [cardiac-specific troponins $\mathrm{T}$ or I, or muscle and brain fraction of creatine kinase (CK-MB)]. While in UA no such biomarker can be detected in the bloodstream hours after the initial onset of ischemic chest pain. ${ }^{2}$ Patients with suspected acute coronary syndrome should be assessed immediately by an appropriate healthcare professional. 


\section{Pharmacotherapy of ACS}

Standard guidelines recommend a door-to-balloon time time from first medical contact to primary percutaneous coronary intervention (PCI) - of less than 90 minutes (according to the ACCF/AHA) or 60 minutes (according to the ESC) for patients presenting with STEMI.
Significant reductions in mortality were noted between 1995 and 2015, largely attributed to reductions in time from symptom onset to first medical contact, greater use of reperfusion therapy, continuous multi-lead ST-segment monitoring, frequent measurement of vital signs and guideline recommended pharmacotherapy. ${ }^{3}$

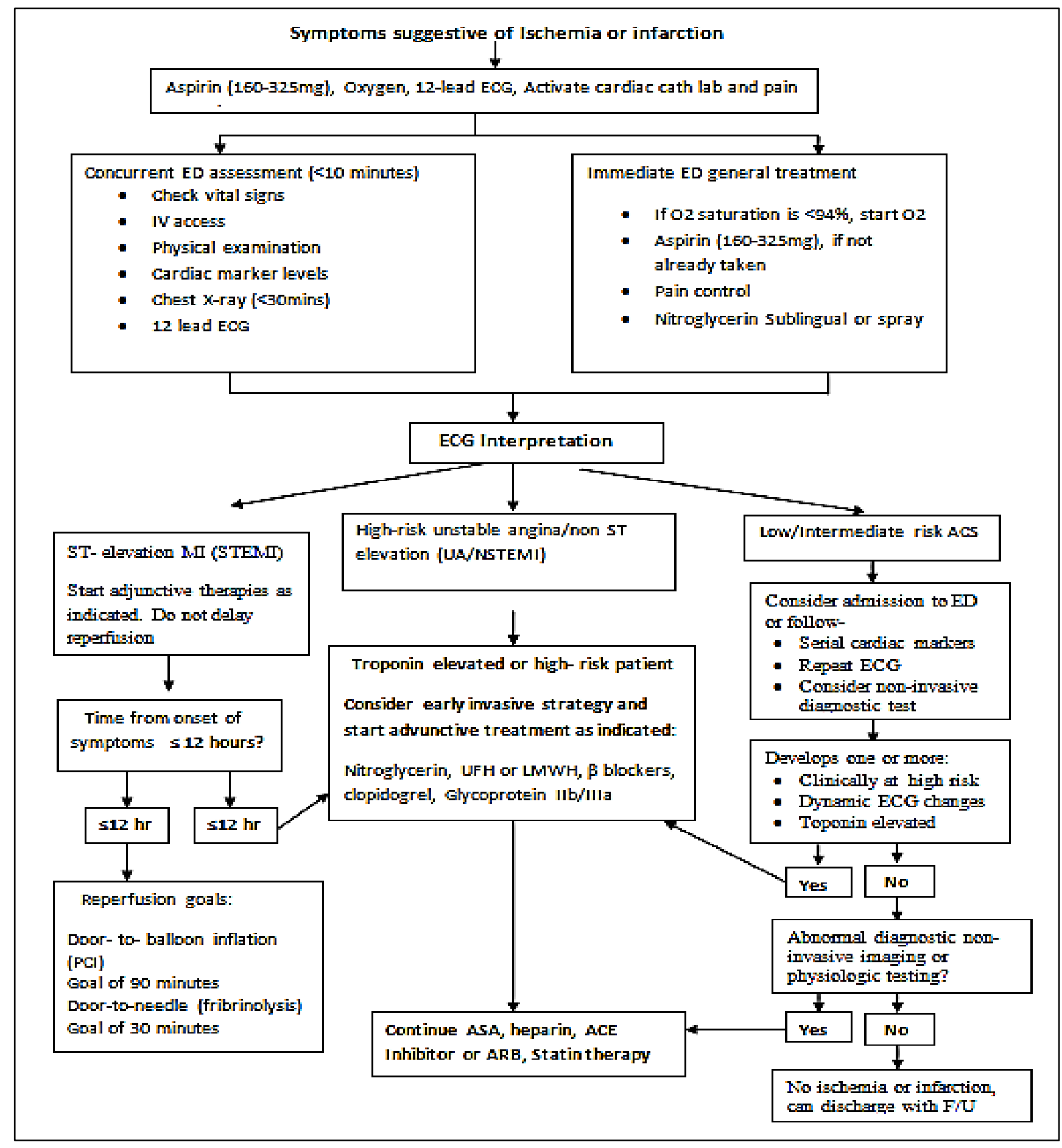

Figure 1: Emergency medical services and hospital preparation for ACS patients. ${ }^{40}$ 
The goal of pharmacological anti-ischaemic therapy is to decrease myocardial oxygen demand (secondary to a decrease in heart rate, blood pressure, preload or myocardial contractility) or to increase myocardial oxygen supply (by administration of oxygen or through coronary vasodilation). If, following treatment, the patient does not rapidly become free of ischaemic signs or symptoms, immediate coronary angiography is recommended independently of ECG findings and cardiac troponin levels. In patients whose ischaemic symptoms are not relieved by nitrates and beta-blockers, opiate administration is reasonable while waiting for immediate coronary angiography, with the caveat that morphine may slow intestinal absorption of oral platelet inhibitors. ${ }^{4}$

The efficacy of pharmacological therapy at symptom onset, throughout hospitalization, and at discharge is the important criteria for treatment of ACS. ${ }^{4}$ Pharmacotherapy for early treatment of ACS are outlined in Figure1. Various medications that impact the function of coronary disease include nitrates (intravenous, oral, and topical), beta blockers, calcium channel blockers, ranolazine therapy, warfarin/new anticoagulants, angiotensin-converting enzyme inhibitors, angiotensin receptor blockers, aldosterone, diuretics, statins, and other lipid-lowering medications, nonsteroidal antiinflammatory drugs, insulin, oral hypoglycemics, influenza, and pneumococcal immunizations. ${ }^{5}$

\section{Reperfusion therapy}

Reperfusion therapy is the cornerstone of STEMI management and should be instituted in all patients presenting within 12 hours of onset of symptoms. The most efficacious reperfusion therapy available is timely primary PCI, but it may not be the most effective in the Indian context, given the relative paucity of PCI-capable centers. Fibrinolytic therapy therefore remains the most practicable reperfusion strategy for India. The most recent data from India suggests that only about $8 \%$ of patients with STEMI receive primary PCI. Nearly $60 \%$ of patients receive fibrinolysis with streptokinase as initial treatment. $^{6}$

\section{Fibrinolytic agent}

In ST segment elevated MI, streptokinase has been the most commonly used fibrinolytic agent in India. Recently, there is some favourable evidence for the use of tenecteplase in Indian settings. Tenecteplase has the advantage of being fibrin specific, can be given as a bolus dose, and has a lower incidence of hypersensitivity reactions. TIMI 3 flow in the infarct related coronary artery may also occur more frequently with tenecteplase when compared to streptokinase. Tenecteplase should be administered at a dose of $0.5 \mathrm{mg} / \mathrm{kg}$ body weight. Fibrinolytic (thrombolytic) therapy using streptokinase, urokinase, tenecteplase or any other agent should not be used in patients with UA and NSTEMI. ${ }^{6}$

\section{Beta blockers}

Beta-blockers have long been a mainstay for the treatment of acute coronary syndromes (ACS). Betablockers competitively inhibit the myocardial effects of circulating catecholamines and reduce myocardial oxygen consumption by lowering heart rate, blood pressure and myocardial contractility. ${ }^{4}$ ACC/AHA guidelines have been revised to make intravenous beta-blockers a class IIa indication for appropriate subjects with ACS (both STEMI as well as NSTEMI). ${ }^{7}$ They reduce the rate of progression to myocardial infarction by $13 \%$. Given their secondary preventative benefits in patients with a recent myocardial infarction, beta blockers should be the first line anti-anginal agent of choice in patients with non-ST elevation ACS. In the absence of bradycardia or hypotension, patients with an acute coronary syndrome in Killip class I should be considered for immediate intravenous and oral beta blockade. 8 Oral beta blockers should be started as soon as possible. Suitable agents and doses include metoprolol $25-50 \mathrm{mg}$ twice daily and bisoprolol 2.5-5 $\mathrm{mg}$ once daily.

Beta-blockers should not be administered in patients with symptoms possibly related to coronary vasospasm or cocaine use, as they might favour spasm by leaving alpha-mediated vasoconstriction unopposed by betamediated vasodilation. ${ }^{4}$ Also they are contraindicated in cardiogenic shock, bradycardia HR<60/min; hypotension $\mathrm{BP}<100 \mathrm{mmHg}$ systolic, any clinical or radiographic signs of heart failure; asthma; untreated phaeochromocytoma; sinoatrial or AV nodal dysfunction, $2^{\text {nd }}$ or $3^{\text {rd }}$ degree block; severe COPD; severe peripheral vascular disease.

Patients already on a beta blocker should continue the drug if free of above listed contraindications. Beta blocker therapy should be stopped if a contraindication develops but can be restarted at a later if the patient is clinically stable. ${ }^{9}$

\section{Aspirin and clopidogrel combination therapy}

Atherosclerosis is a chronic inflammatory process that is known to be the underlying cause of coronary artery disease $(C A D){ }^{10}$ Platelets play a pivotal role in the thrombotic process that follows rupture, fissure, or erosion of an atherosclerotic plaque. ${ }^{11}$ Because atherothrombotic events are essentially platelet-driven processes, this underscores the importance of antiplatelet agents, which represent the cornerstone of treatment, particularly in the patients with acute coronary syndromes (ACS) and undergoing percutaneous coronary intervention (PCI). For over a decade, dual antiplatelet therapy (DAPT) with aspirin and clopidogrel has been considered the standard of care in the setting of ACS and PCI. Synergy between clopidogrel and aspirin is biologically plausible because they act through independent mechanisms. Their combination inhibits ADP-induced platelet activation and thromboxane A2 
production, 2 different pathways that affect platelet aggregability. ${ }^{12}$ Clopidogrel in Unstable angina to prevent Recurrent Events (CURE), the largest randomized ACS trial to date, tested the efficacy of the combination of aspirin (75 mg to $325 \mathrm{mg} /$ day) and clopidogrel (300 mg loading dose followed by $75 \mathrm{mg} /$ day) showed an increased patency rate of the infarct-related artery and reduced mortality comparing with aspirin alone in patients with ST elevation acute coronary syndrome. ${ }^{12}$ Antiplatelet therapy reduces mortality by reducing the risk of fatal strokes and fatal myocardial infarctions also.

Protease activated receptor-1 (PAR-1) is a primary receptor for thrombin on platelets and is also present on vascular endothelium and smooth muscle cells. Vorapaxar, a novel oral PAR-1 antagonist that inhibits thrombin induced platelet activation. ${ }^{13}$ In non-STsegment elevation acute coronary syndrome patients undergoing $\mathrm{CABG}$, vorapaxar was associated with a significant reduction in ischemic events and no significant increase in major CABG-related bleeding. ${ }^{14}$

\section{Intravenous glycoprotein IIb/IIIa receptor antagonist}

GPIIb/IIIa inhibitors (abciximab, eptifibatide, tirofiban) block platelet aggregation by inhibiting fibrinogen binding to a conformationally activated form of the GPIIb/IIIa receptor on two adjacent platelets. ${ }^{4}$ Glycoprotein IIb/IIIa inhibitors have been shown to increase spontaneous reperfusion in STEMI patients and high risk non-ST elevation patients, particularly if they are undergoing percutaneous coronary intervention. ${ }^{8}$

Recent studies suggest that intracoronary bolus administration of these agents rather than the traditional intravenous route may provide greater benefit as measured by infarct size and extent of microvascular perfusion and obstruction, especially in high-risk patients. $^{15}$ Potential mechanisms include higher local platelet glycoprotein IIb/IIIa receptor occupancy and better post-PCI microvascular perfusion. ${ }^{16}$ Glycoprotein $\mathrm{IIb} / \mathrm{III}$ inhibitor therapy provide protection against acute stent thrombosis and prevent recurrent MI in high risk non-ST segment ACS. ${ }^{17}$

In patients with NSTE-ACS treated with an early invasive strategy and dual antiplatelet therapy (DAPT) with intermediate/high-risk features (e.g., positive troponin), a glycoprotein (GP) IIb/IIIa inhibitor may be considered as part of initial antiplatelet therapy. ${ }^{18}$ Tirofiban and eptifibatide, the agents approved for use in NSTE ACS, are cleared renally, and dosing adjustments based on creatinine clearance are recommended. ${ }^{19}$

\section{Anticoagulant therapy}

Fibrin-linked platelet thrombosis in a coronary artery is at the pathologic root of mycocardial infarction (MI), so antithrombotic therapy is the foundation for the management of ACS. Parenteral anticoagulants- unfractionated heparin, low-molecualr weight heparin, bivalirudin, fondaparinux - all have evidence supported roles in the early medical and interventional management of ACS. The ACC/AHA and ESC guidelines recommend use of antithrombin therapy as an adjunct to aspirin in patients with NSTE ACS without modification based on age (class Ia) however, the efficacy and balance of benefit and risk from the use of these agents may be altered by age-related changes in thrombosis and fibrinolysis. ${ }^{20}$ Anticoagulant therapy should be continued for eight days, or until hospital discharge or coronary revascularisation. ${ }^{8}$

\section{Unfractionated heparin (UFH)}

Unfractionated heparin (UFH) exerts its anticoagulant effect by accelerating the action of circulating antithrombin III (AT-III), a proteolytic enzyme which inactivates Factor IIa (thrombin), Factor IXa, and Factor Xa. The UFH- AT-III complex prevents thrombus propagation but does not lyse existing thrombi. The effect of UFH can be readily and repeatedly measured-in the ED with the aPTT assay and in the cath lab with the activated clotting time (ACT). Weight-adjusted i.v. administration with an initial bolus of 60-70 IU/kg up to a maximum of $5000 \mathrm{IU}$, followed by an infusion of 12-15 $\mathrm{IU} / \mathrm{kg} / \mathrm{h}$ up to a maximum of $1000 \mathrm{IU} / \mathrm{h}$, is recommended. ${ }^{4}$ Still, the disadvantages of UFH are widely recognized namely, its relatively poor bioavailability, which stems from its many nonproductive interactions with plasma proteins and endothelial cells, and its activation of the PF4 receptor on platelets. This may result in heparin- induced thrombocytopenia (HIT) and paradoxical pathologic thrombosis. $^{21}$ UFH has a pharmacokinetic profile with large interindividual variability and a narrow therapeutic window. ${ }^{4}$

\section{Low molecular weight heparin}

Dalteparin and enoxaparin are "low-molecular-weight heparins" (LWMH), which are created through different, proprietary, enzymatic degradations of UFH to smaller chain lengths. The preponderance of LWMH chains retains the ability to link to AT-III and then to Factor Xa, impacting this amplification step in the clotting cascade and therefore inhibiting coagulation. Fewer LMWH chains have the stoichiometric capability to link to AT-III and the much larger thrombin (IIa) moiety, so the relative activity of LMWHs in therapeutic anticoagulation is much greater against Factor Xa than against thrombin. ${ }^{21}$ LMWH has a more predictable dose effect relationship than UFH and causes HIT less frequently.

\section{Enoxaparin}

The LMWH enoxaparin, alternatively, is specifically supported by the most current ACC-AHA Guidelines for both NSTE-ACS and STEMI. For STEMI being managed with fibrinolytic therapy, enoxaparin is preferred over 
UFH (I-A). ${ }^{21}$ The most widely used agent in NSTE-ACS is enoxaparin, $1 \mathrm{mg} / \mathrm{kg}$ administered subcutaneously twice daily, while the dose is reduced to $1 \mathrm{mg} / \mathrm{kg}$ once a day if eGFR, $30 \mathrm{~mL} / \mathrm{min} / 1.73 \mathrm{~m}^{2}$. LMWH should not be administered in patients with eGFR, $15 \mathrm{~mL} / \mathrm{min} / 1.73 \mathrm{~m}^{2} .{ }^{4}$

A Cochrane review of seven randomised controlled trials (RCTs) $(n=11.092)$ reported that low molecular weight heparin treatment (principally enoxaparin) reduced myocardial infarction and coronary revascularisation procedure rates compared to unfractionated heparin. There was no difference in mortality or major bleeding episodes. $^{8}$

\section{Bivalirudin}

Bivalirudin binds directly to thrombin and thereby inhibits the thrombin-induced conversion of fibrinogen to fibrin. It inactivates fibrin-bound as well as fluid-phase thrombin. As the drug does not bind to plasma proteins, its anticoagulant effect is more predictable than that of UFH. ${ }^{4}$ Previously published results from randomized trials (ACUITY in NSTE-ACS, ISAR in NSTEMI, HORIZONS-AMI in STEMI) have consistently demonstrated a reduced risk of bleeding and improved overall outcomes with bivalirudin rather than unfractionated heparin (UFH) in ACS patients, giving bivalirudin a class $1 \mathrm{~b}$ recommendation (from ACCF/AHA) as an adjunctive therapy in patients with ACS undergoing primary PCI. ${ }^{22}$ Bivalirudin has the ability to reduce bleeding risk. ${ }^{13}$

\section{Fondaparinux}

The parenteral selective factor Xa inhibitor fondaparinux is a synthetic pentasaccharide that binds reversibly and non-covalently to antithrombin with high affinity, thereby preventing thrombin generation. The compound has $100 \%$ bioavailability after s.c. injection, with an elimination half-life of 17 hours, allowing once-daily dosing. 4

At therapeutic doses, fondaparinux exerts very limited effects on routine haemostasis tests, including activated partial thromboplastin time and activated clotting time. Moreover, the drug exhibits no effect on platelets and there is no need to monitor platelet count, as the risk of immunoallergic thrombocytopenia is negligible, if not nil. ${ }^{13}$ Once-daily $2.5 \mathrm{mg}$ dose is recommended in all patients with ACS, with no dose-adjustment and no laboratory monitoring, regardless of patient type. ${ }^{23}$

\section{Nitrates}

Nitrates promote the release of nitric oxide from the endothelium, which results in venous and arterial vasodilation. Venodilation lowers preload and myocardial oxygen demand. Arterial vasodilation may lower blood pressure, thus reducing myocardial oxygen demand. Arterial vasodilation also relieves coronary artery vasospasm, dilating coronary arteries to improve myocardial blood flow and oxygenation. One SL nitroglycerin (NTG) tablet should be administered every 5 minutes for up to three doses to relieve myocardial ischemia. If patients have previously been prescribed sublingual NTG and ischemic chest discomfort persists for more than 5 minutes after the first dose, the patient should be instructed to contact emergency medical services before self-administering subsequent doses in order to activate emergency care sooner. IV NTG then should be initiated in all patients with an ACS who do not have a contraindication and who have persistent ischemic symptoms, heart failure, or uncontrolled blood pressure, and should be continued for approximately 24 hours after ischemia is relieved. Importantly, other life-saving therapy, such as ACE inhibitors or beta blockers, should not be withheld because the mortality benefit of nitrates is unproven. Nitrates play a limited role in the treatment of ACS patients because two large, randomized clinical trials failed to show a mortality benefit for IV followed by oral nitrate therapy in acute MI. The most significant adverse effects of nitrates are tachycardia, flushing, headache and hypotension. Nitrate administration is contraindicated in patients who have received oral phosphodiesterase-5 inhibitors, such as sildenafil and vardenafil within the past 24 hours and tadalifil within the past 48 hours. SL followed by IV NTG should be administered to all patients with non-ST-segmentelevation ACS in the absence of contraindications like hypotension. ${ }^{24}$

\section{ACE inhibitors/angiotensin receptor blockers (ARB)}

ACE inhibitors should be initiated in all patients following MI to reduce mortality, decrease reinfarction, and prevent the development of heart failure. ${ }^{25}$ The benefit of ACE inhibitors in patients with MI most likely comes from their ability to prevent cardiac remodelling. Other proposed mechanisms include improvement in endothelial function, a reduction in atrial and ventricular arrhythmias, and promotion of angiogenesis, leading to a reduction in ischemic events. The largest reduction in mortality is observed for patients with LV dysfunction [low LV ejection fraction (EF)] or heart failure symptoms. ACE inhibitor prescription at hospital discharge following $\mathrm{MI}$, in the absence of contraindications, to patients with depressed LV function (ejection fraction $<40 \%$ ) is currently a quality care indicator. $^{26}$

In the heart outcome prevention evaluation (HOPE) trial, ramipril significantly reduced the risk of death, MI, or stroke in high-risk patients aged with chronic CAD or with diabetes and cardiovascular risk factor. ${ }^{27}$ Based on the extensive benefit of ACE inhibitors in patients with $\mathrm{CAD}$, their routine use should be considered in all patients following an ACS in the absence of a contraindication. 
Patients showing adverse reaction to an ACE inhibitor (i.e hypotension, cough, clinical signs of heart failure or LVEF) should be prescribed an angiotensin receptor blocker (ARB) ${ }^{25}$ Both candesartan and valsartan have improved outcomes in clinical trials in patients with heart failure. $^{28}$

Other less common but more serious adverse effects of ACE inhibitors include acute renal failure, hyperkalemia, severe aortic stenosis and angioedema.

\section{Statins}

Statins improve prognosis in coronary artery disease. Statins are recommended for all NSTE ACS patients, irrespective of cholesterol levels, initiated early after admission, with the aim of achieving LDL $\mathrm{C}$ levels $<70$ $\mathrm{mg} / \mathrm{dl}$. Atorvastatin is usually the preferred agent, at a dose of $80 \mathrm{mg}$ per day. ${ }^{6}$

\section{Aldosterone antagonist}

Aldosterone antagonist therapy is recommended in patients with LV dysfunction (LVEF $\leq 40 \%$ ) and heart failure or diabetes after NSTE-ACS. Spironolactone 25$50 \mathrm{mg}$ od or eplerenone $25-50 \mathrm{mg}$ od has been shown to reduce morbidity and mortality in these patients after ACS. ${ }^{29}$ Contra-indicated in hyperkalaemia or renal failure $(\mathrm{Cr}>200 \mu \mathrm{mol} / \mathrm{l})$. Caution in hypotension and monitor potassium levels. ${ }^{9}$

\section{Morphine}

If the patient's pain hasn't improved after administration of nitroglycerin, morphine sulfate may be given at an initial dose of a 2 to $4 \mathrm{mg}$ IV push that can be repeated every five to 15 minutes until the pain is controlled. Morphine causes venous and arteriolar vasodilation, reducing both preload and afterload, and the drug's analgesic properties decrease the pain and anxiety associated with ACS. However, morphine can cause hypotension and respiratory depression, so the patient's blood pressure level, respiratory rate, and $\mathrm{SaO}_{2}$ level for changes should be closely monitor. ${ }^{30}$ Morphine is the preferred analgesic for patients with STEMI (class I, LOE C). However, analysis of retrospective registry data raised a question about the potentially adverse effects of morphine in patients with UA/NSTEMI. As a result, the ACC AHA UA/NSTEMI writing group reduced morphine use to a Class IIa recommendation for that patient population. $^{31}$

\section{Oxygen}

Supplemental oxygen should be initiated only if the patient has breathlessness, hypoxaemia $\left(\mathrm{SpO}_{2}<94 \%\right)$ or signs of heart failure or shock. The use of oxygen saturation monitoring by noninvasive techniques such as pulse oximetry, may be very useful in guiding oxygen therapy (weak recommendation, very-low-quality evidence). However, it is important to understand that there is evidence that hyperoxaemia is potentially harmful in uncomplicated myocardial infarction. ${ }^{32}$

\section{Summary of advances}

\section{Monoclonal antibodies}

Several new therapies and drug strategies for patients with ACS are under investigation. A phase 2 trial (SELECT-ACS) examined a novel P-selectin (a celladhesion molecule expressed on endothelial cells and platelets) monoclonal antibody, inclacumab, in patients with NSTE-ACS undergoing PCI. ${ }^{33}$ This trial showed significant reductions in troponin I levels after infusions of inclacumab suggestive of potential to reduce myocardial damage.

\section{Stem cell therapy}

The use of stem cells derived from bone marrow or myocardium to improve cardiac function has been a promising area of research and speculation. Larger trials like achieve myocardial regeneration (ALLSTAR, allogeneic cardiac stem cells) and Bone Marrow Cells in Acute Myocardial Infarction (BAMI, autologous bone marrow cells) are on-going and are expected to shed light on some of this unanswered queries. ${ }^{34}$

\section{Hemodynamic support in percutaneous coronary intervention}

There has been an on-going debate regarding the utilization of intra-aortic balloon pump (IABP) counter pulsation to support high-risk PCI. Even though there has been a lack of convincing evidence of improvement in outcomes, IABP support continues to be routinely utilized for high-risk patients with myocardial infarction and cardiogenic shock, and international guidelines had given it a class I indication. Despite its limitations, this trial provides reasonably strong evidence against the routine use of IABP after PCI in the setting of cardiogenic shock. ${ }^{13}$

\section{Percutaneous coronary intervention access: radial versus femoral}

Patient convenience and the substantial reduction of the risk of bleeding associated with PCI from the trans-radial route have made it popular and comparable to a femoral approach for PCI and have been seen in observational studies. RIFLE-STEACS (radial versus femoral randomized investigation in ST-elevation acute coronary syndrome) randomized patients with STEMI to receive primary PCI via radial or femoral access. ${ }^{35}$ High-risk patients with cardiogenic shock were also included in this study unlike in the RIVAL trial. The results revealed a $60 \%$ relative reduction in cardiac death via radial access as compared to femoral access (5.3\% versus 9.2\%). These differences were attributed to a reduction in mainly 
access site bleeding after a radial access PCI. Lastly, the RADIAL-STEMI trial randomized 707 patients with STEMI at four centres in the Czech Republic. The investigators reported an $80 \%$ reduction in 30 day bleeding and access site complication rate after radial access PCI (1.4\% versus $7.2 \%)$. Additionally, there was a reduction in contrast load and ICU length of stay after PCI via the radial approach. These trials provide consistent and convincing evidence that the radial approach for PCI reduces bleeding and access site complications, and improves net outcomes in patients with STEMI. In addition, the radial approach is cheaper, and allows for early patient ambulation, recovery and hospital discharge as compared to the femoral approach. Another interesting conclusion from these studies was the association between improved outcomes and increased procedural experience with radial PCI on the part of interventionists. $^{13}$

\section{Thrombus aspiration before percutaneous coronary intervention}

Current ACCF/AHA guidelines recommend routine thrombus aspiration before primary PCI in STEMI (Class IIa) based on the available evidence supporting this therapy. ${ }^{36}$ There were no differences in all-cause mortality at the end of 30 days which were also noted in the TAPAS trial. Another randomized study - trial of routine aspiration thrombectomy with PCI versus PCI Alone in patients with STEMI Undergoing Primary PCI (Total) is currently underway. ${ }^{13}$

\section{Stent type}

DES (Drug eluting stent) has been shown to have superior efficacy as compared to bare-metal stents (BMS). Second generation Everolimus-eluting stents were associated with a lower incidence of stent thrombosis, target vessel revascularization and less cardiac side effects as compared to $\mathrm{BMS}^{37}$ Due to improved outcomes and reduction in late stent thrombosis with the newer generation DES, the need for DAPT after PCI may be reduced and a major randomized trial is currently underway to determine the optimal duration of DAPT. $^{38}$

\section{Bleeding risk}

Evidence suggests that a higher incidence of bleeding in patients with ACS undergoing revascularization increases mortality. Bleeding risk is especially high in patients with an indication for anticoagulation (atrial fibrillation, mechanical valve, venous thromboembolism) that undergo PCI. Results from the WOEST trial indicate that in patients with an established and absolute indication for oral anticoagulant (OAC) who undergo PCI, $\mathrm{OAC}+$ clopidogrel is associated with a reduced risk of bleeding with maintained efficacy (no increase in the incidence of myocardial infarction or stent thrombosis) and should therefore be the preferred approach over
OAC+aspirin+clopidogrel. ${ }^{39}$ After a 1-year follow-up period, there were significantly fewer bleeding events (primary endpoint) in the double therapy group as compared to the triple therapy group $(19.4 \%$ versus 44.4\%, HR: 0.36). Future studies are needed in the ACS subset of patients to establish the ideal dose and duration of antithrombotic agents that minimize bleeding without compromising efficacy.

\section{CONCLUSION}

ACS is a potentially life-threatening condition that affects millions of individuals each year. Despite declining rates of hospitalization for MI, the identification and prevention of ACS continues to be an important public health concern. Over the past several years, studies have led to an improved understanding of the pathophysiology of ACS and advancements have been made in the medical management of this condition. Initial ACS management should include risk stratification, appropriate pharmacologic management including DAPT, anticoagulation and appropriate adjuvant therapies, and a decision to pursue an early invasive or conventional treatment strategy. Long-term management following an ACS event should follow evidence-based recommendations and should be individualized to each patient.

\section{Funding: No funding sources Conflict of interest: None declared Ethical approval: Not required}

\section{REFERENCES}

1. Nag T, Ghosh A. Cardiovascular disease risk factors in Asian Indian population: a systematic review. J Cardiovasc Dis Res. 2013;4(4):222-8.

2. Kumar A, Cannon CP. Acute coronary syndromes: diagnosis and management, part I . Mayo Clin Proc. 2009;84(10):917-38.

3. Puymirat E, Simon T, Steg PG, Schiele F, Guéret P, Blanchard D, et al. Association of changes in clinical characteristics and management with improvement in survival among patients with ST-elevation myocardial infarction. JAMA. 2012;308(10):998100.

4. Roffi M, Patrono C, Collet JP, Mueller C. ESC guidelines for the management of acute coronary syndromes in patients presenting without persistent ST-segment elevation. European Heart Journal. 2015:1-59.

5. Cannon CP, Brindis RG, Chaitman BR, Cohen DJ. ACCF/AHA key data elements and definitions for measuring the clinical management and outcomes of patients with acute coronary syndromes and coronary artery disease. Circulation. 2013;127:1052-89.

6. Daga LC, Kaul U, Mansoor A. Approach to STEMI and NSTEMI. Supplement JAPI. 2011;59:19-25.

7. Chatterjee S, Chaudhuri D, Vedanthan R, Fuster V. Early intravenous beta-blockers in patients with acute 
coronary syndrome - a meta-analysis of randomized trials. Int J Cardiol. 2013;168(2):915-21.

8. Scottish Intercollegiate Guidelines Network (SIGN). Acute coronary syndrome. Edinburgh: SIGN; 2013. Available at URL: http://www.sign.ac.uk.

9. Acute coronary syndrome guideline, 2015. Available at http://www.worcsacute.nhs.uk.

10. Hansson GK. Inflammation, atherosclerosis, and coronary artery disease. $\mathrm{N}$ Engl $\mathrm{J}$ Med. 2005;352:1685-895.

11. Davì G, Patrono C. Platelet activation and atherothrombosis. N Engl J Med. 2007;357:2482-94.

12. Jneid H, Bhatt DL, Corti R, Badimon JJ. Aspirin and Clopidogrel in Acute coronary syndromes therapeutic insights from the cure study free. Arch Intern Med. 2003;163(10):1145-53.

13. Acute coronary syndrome Management Strategies: Recent advances, 2014. Available at http://www.csi.org.in/Cardio_pdf/SEC_1/Ch-22.pdf.

14. Whellan DJ, Tricoci P, Chen E, Huang Z, Leibowitz DJ. Vorapaxar in acute coronary syndrome patients undergoing coronary artery bypass graft surgery: subgroup analysis from the TRACER trial. Thrombin Receptor Antagonist for Clinical Event Reduction in Acute Coronary Syndrome. Am Coll Cardiol. 2014;63(11):1048-57.

15. Stone GW, Maehara A, Witzenbichler B, Godlewski J, Parise H, Dambrink $\mathrm{JH}$, et al. Intracoronary abciximab and aspiration thrombectomy in patients with large anterior myocardial infarction. The INFUSE-AMI randomized trial. JAMA. 2012;307:1817-26.

16. Deibele AJ, Jennings LK, Tcheng JE, Neva C. Intracoronary eptibatide bolusadministration during percutaneous coronary revascularization for acute coronary syndromes with evaluation of platelet glycoprotein IIb/IIIa receptor occupancy and platelet function: the intracoronary eptibatide (ICE) trial. Circulation. 2010;121(6):784-91.

17. Hong MK. Recent advances in the treatment of STsegment elevation myocardial infarction. Scientifica. 2012:1-13

18. Amsterdam EA, Wenger NK, Brindis RG, Casey D. AHA/ACC Guideline for the Management of Patients With Non-ST-Elevation Acute Coronary Syndromes: Executive Summary. J Am Coll Cardiol. 2014;64(24):2645-87.

19. Gretler DD, Guerciolini R, Williams PJ. Pharmacokinetic and pharmacodynamic properties of eptifibatide in subjects with normal or impaired renal function. Clin Ther. 2004;26:390-8.

20. Braunwald E, Antman EM, Beasley JW, Califf RM, Cheitlin MD. ACC/AHA guideline update for the management of patients with unstable angina and non-ST-segment elevation myocardial infarction2002: summary article: a report of the American College of Cardiology/American Heart Association Task Force on Practice Guidelines. Committee on the Management of Patients with Unstable Angina. Circulation. 2002;106:1893-1900.
21. Pollack CV. Anticoagulation in acute coronary syndrome and beyond. Available at http://www.emcreg.org/publications/monographs/201 0/2010mono_cvp.pdf.

22. O'Gara PT, Kushner FG, Ascheim DD, Casey DE, Chung MK, de Lemos JA, et al. ACCF/AHA guideline for the management of ST-elevation myocardial infarction: a report of the American College of Cardiology Foundation/American Heart Association Task Force on Practice Guidelines. J Am Coll Cardiol. 2013;61(4):78-140.

23. Bassand JP. The place of fondaparinux in the ESC and ACC/AHA guidelines for anticoagulation in patients with non-ST elevation acute coronary syndromes. European Heart Journal Supplements. 2008;10 (Supplement C):C22-29.

24. Spinler SA, de Denus S. Acute coronary syndrome. In: Joseph di Piro, Robert Talbet, Gary C Yee eds. Pharmacotherapy: A Pathophysiologic Approach. $9^{\text {th }}$ ed. NY: Mc GrawHill; 2014:291-319.

25. Antman EM, Anbe DT, Armstrong PW, Bates ER, Green LA, Hand M, et al. ACC/AHA guidelines for the management of patients with ST-elevation myocardial infarction: executive summary. A report of the American College of Cardiology/American Heart Association Task Force on Practice Guidelines (Committee to revise the 1999 Guidelines for the Management of Patients with Acute Myocardial Infarction). Circulation. 2004;110:588-636.

26. The Global Use of Strategies to Open Occluded Coronary Arteries (GUSTO) Investigators. An international randomized trial comparing four thrombolytic strategies for acute myocardial infarction. N Engl J Med. 1993;329:673-82.

27. Yusuf S, Sleight P, Pogue J, Bosch J, Davies R, Dagenais G. Effects of an angiotensin-converting enzyme inhibitor, ramipril, on cardiovascular events in high-risk patients. The Heart Outcomes Prevention Evaluation Study Investigators. $\mathrm{N}$ Engl $\mathrm{J}$ Med. 2000;342:145-53.

28. Pfeffer MA, McMurray JJV, Velazquez EJ, Rouleau JL, Køber L, Maggioni AP, et al. Valsartan, captopril, or both in myocardial infarction complicated by heart failure, left ventricular dysfunction, or both. N Engl J Med. 2003;349:1893906.

29. Zannad F, McMurray JJ, Krum H, van Veldhuisen DJ. Eplerenone in patients with systolic heart failure and mild symptoms. N Engl J Med. 2011;364:11-21.

30. Overbaugh KJ. Acute coronary syndrome. AJN. 2009;109(5):42-52.

31. Meine TJ, Roe MT, Chen AY, Patel MR, Washam JB. Association of intravenous morphine use and outcomes in acute coronary syndromes: results from the CRUSADE quality improvement initiative. Am Heart J. 2005;149:1043-9.

32. Welsford M, Nikolaou NI, Beygui F, Bossaert L, Ghaemmaghami C, Nonogi $\mathrm{H}$, et al. Part 5: acute coronary syndromes: 2015 International Consensus on Cardiopulmonary Resuscitation and Emergency 
Cardiovascular Care Science with Treatment Recommendations. Resuscitation. 2015;95:e121-46.

33. Tardif JC, Tanguay JF, Wright SR, Duchatelle V, Petroni T, Grégoire JC, et al. Effects of the P-selectin antagonist inclacumab on myocardial damage after percutaneous coronary intervention for non-STsegment elevation myocardial infarction: results of the SELECT-ACS trial. J Am Coll Cardiol. 2013;61(20):2048-55.

34. Aggarwal B, Menon V. Recent advances in treatment of acute coronary syndromes. F1000 Prime Rep. 2013;5-56.

35. Romagnoli E, Biondi-Zoccai G, Sciahbasi A, Politi L, Rigattieri S, Pendenza G, et al. Radial versus femoral randomized investigation in ST-segment elevation acute coronary syndrome: the RIFLESTEACS (Radial Versus Femoral Randomized Investigation in ST Elevation Acute Coronary Syndrome) study. J Am Coll Cardiol 2012;60(24):2481-9.

36. Vlaar PJ, Svilaas T, van der Horst IC, Diercks GF, Fokkema ML, de Smet BJ, et al. Cardiac death and reinfarction after 1 year in the Thrombus Aspiration during Percutaneous coronary intervention in Acute myocardial infarction Study (TAPAS): a 1-year follow-up study. Lancet. 2008;371(9628):1915-20.
37. Sabate M, Cequier A, Iñiguez A, Serra A, Hernandez-Antolin R, Mainar V, et al. Everolimuseluting stent versus bare-metal stent in ST-segment elevation myocardial infarction examination: 1 year results of a randomized controlled trial. Lancet. 2012;380(9852):1482-90.

38. Feres F, Costa RA, Bhatt DL, Leon MB, Botelho RV, King SB, et al. Optimized duration of clopidogrel therapy following treatment with the Endeavor zotarolimus-eluting stent in real-world clinical practice optimize trial: rationale and design of a large-scale, randomized, multicenter study. Am Heart J. 2012;164(6):810-6.e3.

39. Dewilde WJ, Oirbans T, Verheugt FW, Kelder JC, De Smet BJ, Herrman JP, et al. Use of clopidogrel with or without aspirin in patients taking oral anticoagulant therapy and undergoing percutaneous coronary intervention: an open-label, randomised, controlled trial. Lancet. 2013;381(9872):1107-15.

40. O'Connor RE, Al Ali AS, Brady WJ, Ghaemmaghami CA, Menon V, Welsford M. Part 9: acute coronary syndromes: 2015 American Heart Association Guidelines Update for Cardiopulmonary Resuscitation and Emergency Cardiovascular Care. Circulation. 2015;132(suppl2):S483-S500.

Cite this article as: Thaker V, Patel K. Recent advances in pharmacotherapy of acute coronary syndrome. Int J Basic Clin Pharmacol 2016;5:16951703. 